CrossMark \&lick for updates

Cite this: Dalton Trans., 2015, 44 1193

\section{Acidity enhancement of unsaturated bases of group 15 by association with borane and beryllium dihydride. Unexpected boron and beryllium Brønsted acids $\uparrow$}

\begin{abstract}
Ana Martín-Sómer, ${ }^{a}$ Otilia Mó, ${ }^{a}$ Manuel Yáñez ${ }^{* a}$ and Jean-Claude Guillemin ${ }^{\star b}$
The intrinsic acidity of $\mathrm{CH}_{2}=\mathrm{CHXH}_{2}, \mathrm{HC} \equiv \mathrm{CXH}_{2}(X=N, \mathrm{P}, \mathrm{As}, \mathrm{Sb})$ derivatives and of their complexes with $\mathrm{BeH}_{2}$ and $\mathrm{BH}_{3}$ has been investigated by means of high-level density functional theory and molecular orbital $a b$ initio calculations, using as a reference the ethyl saturated analogues. The acidity of the free systems steadily increases down the group for the three series of derivatives, ethyl, vinyl and ethynyl. The association with both beryllium dihydride and borane leads to a very significant acidity enhancement, being larger for $\mathrm{BeH}_{2}$ than for $\mathrm{BH}_{3}$ complexes. This acidity enhancement, for the unsaturated compounds, is accompanied by a change in the acidity trends down the group, which do not steadily decrease but present a minimum value for both the vinyl- and the ethynyl-phosphine. When the molecule acting as the Lewis acid is beryllium dihydride, the $\pi$-type complexes in which the $\mathrm{BeH}_{2}$ molecules interact with the double or triple bond are found, in some cases, to be more stable, in terms of free energies, than the conventional complexes in which the attachment takes place at the heteroatom, $\mathrm{X}$. The most important finding, however, is that $\mathrm{P}, \mathrm{As}$, and $\mathrm{Sb}$ ethynyl complexes with BeH2 do not behave as $\mathrm{P}, \mathrm{As}$, or Sb Brønsted acids, but unexpectedly as Be acids.
\end{abstract}

Received 28th July 2014,

Accepted 31st October 2014

DOI: $10.1039 / c 4 d t 02292 k$

www.rsc.org/dalton form complexes with borane ${ }^{30,32}$ or alane, ${ }^{31}$ their intrinsic acidity changes dramatically, in most cases sixteen orders of magnitude in terms of the equilibrium acidity constant. ${ }^{30,32}$ These acidity enhancements are even larger when the Lewis acid is a beryllium derivative, ${ }^{34}$ an electron deficient system, that as borane or alane behaves as a very strong Lewis acid. Some evidence seems to indicate that the effect depends on the nature of the Lewis base active site, since in general it has been found that the acidity enhancement is about twice as large in amine-boranes ${ }^{32}$ than in phosphine-boranes. ${ }^{30}$

There are four aims of this paper: (i) to investigate the acidity trends down group 15 of elements, more specifically when the heteroatom is directly bonded to an unsaturated moiety, in particular to a vinyl or to an ethynyl group, (ii) to analyze the effect that the association of these compounds either with $\mathrm{BH}_{3}$ or $\mathrm{BeH}_{2}$ has on their intrinsic acidities, (iii) to explore whether reactivity changes are directly related to the deformation of the base, the acid or both, and (iv) to explore the possibility that this association may lead to a change in the nature of the group losing the proton. For this purpose we will analyze, through the use of density functional theory and $a b$ initio molecular orbital methods, the structure of $\mathrm{H}_{2} \mathrm{C}=\mathrm{CHXH}_{2}$ and $\mathrm{HC} \equiv \mathrm{CXH}_{2}(\mathrm{X}=\mathrm{N}, \mathrm{P}, \mathrm{As}, \mathrm{Sb})$ compounds and their respective deprotonated forms, as well as those of their complexes with $\mathrm{BH}_{3}$ and $\mathrm{BeH}_{2}$ and their deprotonated 
structures. Although these complexes may not be very stable, two of them, namely $\mathrm{H}_{2} \mathrm{C}=\mathrm{CHPH}_{2}: \mathrm{BH}_{3}$ and $\mathrm{HC} \equiv \mathrm{CPH}_{2}: \mathrm{BH}_{3}$, have already been synthesized and spectroscopically characterized, ${ }^{35,36}$ and some rather stable complexes between $\mathrm{N}$-bases and $\mathrm{BeCl}_{2}$ have also been reported. ${ }^{37}$

In our study we will consider not only the possibility of losing the proton from the $\mathrm{XH}_{2}$ group but also from the $\mathrm{BH}_{3}$ or $\mathrm{BeH}_{2}$ ones. Since, it would be interesting to know whether unsaturation has some significant effect on the phenomena to be investigated, we have also included a series of saturated ethyl derivatives as a suitable reference.

\section{Computational details}

In our survey we have employed a theoretical model which has been proven to be rather reliable for the description of protonation and deprotonation processes, and, at the same time, is not very time consuming. ${ }^{38,39}$ Such a model is based on the use of fully optimized geometries obtained using the B3LYP hybrid functional and a $6-31+G(d, p)$ basis set expansion. Final energies are then evaluated in single point calculations using the same functional but a larger $6-311+\mathrm{G}(3 \mathrm{df}, 2 \mathrm{p})$ basis set. The harmonic vibrational frequencies obtained in the B3LYP/ $6-31+G(d, p)$ geometry optimizations are used to ensure that the stationary points of the potential energy surface are local minima, and to evaluate thermal corrections at $298.2 \mathrm{~K}$ necessary to determine the enthalpies and the free energies of the deprotonation processes. This theoretical model has been proven to provide reliable results for similar complexes when compared with experimental values and high-level $a b$ initio methods such as G3 and G4 theories. ${ }^{30,32}$ Nevertheless we have assessed its reliability to reproduce the gas-phase acidities of the systems under investigation in this paper using as a reference G4 theory ${ }^{40}$ calculations, for a suitable set of benchmark cases. Obviously, the B3LYP/6-311+G(3df,2p)// B3LYP/6-31+G(d,p) model is not applicable to $\mathrm{Sb}$ containing compounds, for which the aforementioned basis sets are not available, and where relativistic effects cannot be considered negligible. Hence, for the $\mathrm{Sb}$ derivatives we have used the same functional with two effective core potential (ECP) basis sets that account for the most significant relativistic corrections. The smaller Def2-TZVP ECP basis set $^{41}$ was employed for the geometry optimizations and the calculations of the harmonic vibrational frequencies, whereas the single point calculations on these optimized structures were carried out using a larger Def2-QZVP basis set expansion. ${ }^{41}$ To assess the reliability of this model, and using the $\mathrm{BeH}_{2}$ complexes of ethynylstibine as a suitable benchmark system, we have taken as a reference acidities calculated at the $\operatorname{CCSD}(\mathrm{T}) / \mathrm{Def}-\mathrm{QZVP}$ level using the B3LYP/Def2-TZVP optimized geometries.

The bonding in the complexes under scrutiny was analyzed using four different and complementary procedures, the quantum theory of atoms in molecules (QTAIM), ${ }^{42,43}$ the natural bond orbital (NBO) method, ${ }^{44}$ the Localized Molecular orbital Energy Decomposition analysis (LMO-EDA) ${ }^{45}$ and the
Natural Orbitals for Chemical Valence (NOCV). ${ }^{46}$ Within the framework of the QTAIM, we have obtained the molecular graphs for all the complexes investigated. The molecular graphs are defined by the set of critical points, maxima (nuclei), minima (cage critical points) and saddle points (bond or ring critical points) of the electron density together with the bond paths, which correspond to the lines of zero gradient of the density, connecting two maxima and containing a first order saddle point, usually named the bond critical point. The NBO method describes the bonding in terms of natural localized orbitals built as a combination of atomic hybrids, and allows calculation of the Wiberg bond orders. ${ }^{47}$ One of the advantages of this approach is that it allows us to identify intra- or inter-molecular charge transfer processes by a second order analysis of the Fock matrix, which yields the interaction energies between occupied and empty orbitals of the system. In the LMO-EDA approach the total interaction energy is decomposed as

$$
\Delta E_{\text {int }}=\Delta E_{\text {elstat }}+\Delta E_{\text {Ex }+ \text { rep }}+\Delta E_{\text {pol }}+\Delta E_{\text {disp }}
$$

where $\Delta E_{\text {elstat }}$ is the electrostatic term that describes the classical Coulomb interaction of the occupied orbitals of one of the interacting units with those of the other, $\Delta E_{\mathrm{Ex}+\mathrm{rep}}$ corresponds to the repulsive exchange component resulting from the Pauli exclusion principle, $\Delta E_{\text {pol }}$ is the polarization term resulting from the orbital relaxation energy on going from each subunit to the complex, and $\Delta E_{\text {disp }}$ is the dispersion contribution not accounted for at the HF level.

The NOCV is based on the use of the eigenvectors of the deformation density matrix, ${ }^{46}$ and combined with the Extended Transition State (ETS) approach, ${ }^{48}$ it permits to obtain the orbital interaction term in terms of the NOCV eigenvalues. In the ETS-NOCV approach, the interaction energy is decomposed as

$$
\Delta E_{\text {int }}=\Delta E_{\text {elstat }}+\Delta E_{\text {Pauli }}+\Delta E_{\text {orb }}
$$

where the first two terms, $\Delta E_{\text {elstat }}$ and $\Delta E_{\text {Pauli }}$, have similar meanings to those in eqn (1), and are usually named steric interactions. The term $\Delta E_{\text {orb }}$ accounts for the interactions between the occupied molecular orbitals of one subunit with the empty orbitals of the other, and within the same subunit. The ETS-NOCV calculations have been carried out by means of the ADF-2013.01 suite of programs. ${ }^{49}$

\section{Results and discussion}

The optimized geometries of the isolated amines, phosphines, arsines and stibines and their deprotonated anions, as well as those of the complexes they form with $\mathrm{BeH}_{2}$ and $\mathrm{BH}_{3}$ are summarized in Table $\mathrm{S} 1$ of the ESI. $\dagger$

\section{Acidity enhancement}

The calculated intrinsic acidities measured as the Gibbs free energy associated with the reaction

$$
\mathrm{AH} \rightarrow \mathrm{A}^{-}+\mathrm{H}^{+}
$$

are presented in Table 1. 
Table 1 Calculated acidity $\left(\Delta_{\text {acid }} G^{0}, \mathrm{~kJ} \mathrm{~mol}^{-1}\right)$ for $\mathrm{R}-\mathrm{XH}_{2}(\mathrm{R}=$ ethyl, vinyl, ethynyl; $X=N, P, A s, S b$ ) bases and the corresponding $R-$ $\mathrm{XH}_{2}: \mathrm{BeH}_{2}$ and $\mathrm{R}-\mathrm{XH}_{2}: \mathrm{BH}_{3}$ complexes

\begin{tabular}{|c|c|c|c|}
\hline \multicolumn{4}{|l|}{$\Delta_{\text {acid }} G^{0}$} \\
\hline & Free base & $\mathrm{RXH}_{2}: \mathrm{BeH}_{2}$ & $\mathrm{RXH}_{2}: \mathrm{BH}$ \\
\hline \multicolumn{4}{|l|}{$\mathrm{R}=$ Ethyl } \\
\hline $\mathrm{X}=\mathrm{N}$ & $1627(1638.9 \pm 2.9)^{a}$ & 1431 & 1447 \\
\hline $\mathrm{X}=\mathrm{P}$ & $1522(1531 \pm 12)^{b}$ & 1409 & 1435 \\
\hline $\mathrm{X}=\mathrm{As}$ & $1492(1501 \pm 8.8)^{c}$ & 1377 & 1393 \\
\hline $\mathrm{X}=\mathrm{Sb}$ & 1455 & 1357 & 1361 \\
\hline \multicolumn{4}{|l|}{$\mathrm{R}=\mathrm{Vinyl}$} \\
\hline $\mathrm{X}=\mathrm{N}$ & 1533 & 1325 & 1360 \\
\hline $\mathrm{X}=\mathrm{P}$ & $1470[1474]^{d}(1477 \pm 9.6)^{a}$ & $1346[1343]^{d}$ & 1384 \\
\hline $\mathrm{X}=\mathrm{As}$ & $1446[1446]^{d}(1448 \pm 8.8)^{c}$ & $1322[1320]^{d}$ & 1343 \\
\hline $\mathrm{X}=\mathrm{Sb}$ & 1429 & 1316 & 1321 \\
\hline \multicolumn{4}{|c|}{$\mathrm{R}=$ Ethynyl } \\
\hline $\mathrm{X}=\mathrm{N}$ & 1472 & 1282 & 1320 \\
\hline $\mathrm{X}=\mathrm{P}$ & $1445[1451]^{d}(1459 \pm 9.6)^{a}$ & $1319[1315]^{d}$ & 1351 \\
\hline $\mathrm{X}=\mathrm{As}$ & $1418[1419]^{d}(1434 \pm 8.8)^{c}$ & $1291[1292]^{d}$ & 1309 \\
\hline $\mathrm{X}=\mathrm{Sb}$ & $1401[1397]^{e}$ & 1293 & 1290 \\
\hline
\end{tabular}

${ }^{a}$ Exp. value taken from ref. 50. ${ }^{b}$ Exp. value taken from ref. 51. ${ }^{c}$ Exp. value taken from ref. $52 .{ }^{d}$ Values calculated at the G4 level of theory. ${ }^{e}$ Value calculated at the CCSD(T)/Def2-QZVP level of theory.

For the free compounds we have considered deprotonation at all possible acidic sites, $\mathrm{X}, \mathrm{C}_{\alpha}$ and $\mathrm{C}_{\beta}$. In all cases the systems behave as heteroatom acids since independently of the nature of $\mathrm{R}$ or $\mathrm{X}$, the $\mathrm{R}-\mathrm{XH}^{-}$anion was found to be always the most stable one. This is in agreement with what has been found before for several amines ${ }^{32,51}$ and phosphines, ${ }^{30,51}$ as well as for vinylarsine, ${ }^{51,52}$ vinylstibine ${ }^{53}$ and ethynylarsine.

It is worth noting that there is a very good agreement between our calculated acidities and the experimental values, whenever available. Also the estimates of our DFT model are in excellent agreement with the G4 calculated values. It is also apparent that the acidity increases down the group for the three families of compounds, although this effect is attenuated on going from the saturated compounds to the vinyl derivatives and further to the ethynyl ones. Indeed while ethylstibine is predicted to be $172 \mathrm{~kJ} \mathrm{~mol}^{-1}$ more acidic than ethylamine, for the vinyl and the ethynyl analogues this gap is only 104 and $71 \mathrm{~kJ} \mathrm{~mol}^{-1}$, respectively. As expected, the acidity increases as ethyl < vinyl < ethynyl, reflecting the larger electronegativity of the unsaturated groups with respect to the saturated one.

The complexation of the compounds under investigation either with $\mathrm{BeH}_{2}$ or $\mathrm{BH}_{3}$ leads to a significant enhancement of their intrinsic acidities, similar to the ones reported in the literature for other compounds. ${ }^{30,32,34}$ The calculated acidity enhancement is larger for beryllium dihydride complexes than for borane complexes, and it can be easily rationalized through the thermodynamic cycle shown in Scheme 1, which relates the acidity of the free compound, $\mathrm{RXH}_{2}, \Delta_{\mathrm{r}} G_{4}{ }^{0}$, and the acidity of its complexes, $\mathrm{RXH}_{2}: \mathrm{Y}\left(\mathrm{Y}=\mathrm{BeH}_{2}, \mathrm{BH}_{3}\right), \Delta_{\mathrm{r}} G_{2}{ }^{0}$, to the stabilization of the neutral, $\Delta_{\mathrm{r}} G_{1}{ }^{0}$, and the anionic deprotonated compound, $\Delta_{\mathrm{r}} G_{3}{ }^{0}$ upon Y complexation.

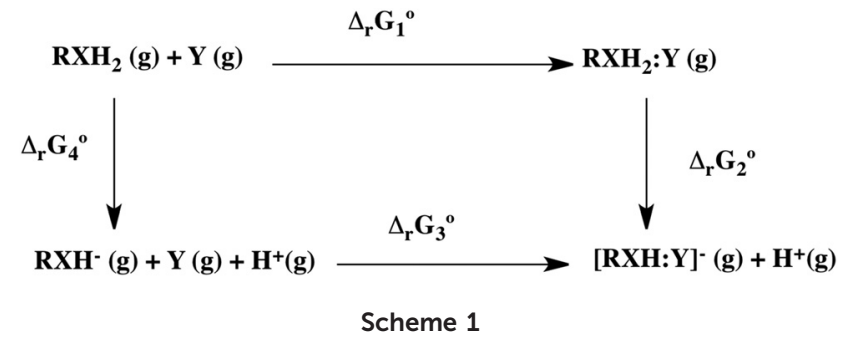

The values of $\Delta_{\mathrm{r}} G_{4}{ }^{0}$ and $\Delta_{\mathrm{r}} G_{2}{ }^{0}$ are summarized in Table 1, since they correspond to the intrinsic acidities of the free compounds and their corresponding complexes, respectively. Those of $\Delta_{\mathrm{r}} G_{1}{ }^{0}$ and $\Delta_{\mathrm{r}} G_{3}{ }^{0}$ are given in Table 2.

The values of $\Delta_{\mathrm{r}} G_{1}{ }^{0}$ and $\Delta_{\mathrm{r}} G_{3}{ }^{0}$ indicate that for both kinds of complexes the acidity enhancement is due to a much larger stabilization of the anion than the neutral, when associated with any of the two Lewis acids. Actually, for both $\mathrm{BH}_{3}$ and $\mathrm{BeH}_{2}$ the strength of the $\mathrm{N}-\mathrm{X}(\mathrm{X}=\mathrm{Be}, \mathrm{B})$ bond dramatically increases on going from the neutral complex to the deprotonated one. This is well reflected in both, the values of the electron densities at the N-X BCPs and in the Wiberg bond orders. As shown in Fig. 1, using the complexes with vinylamine as suitable examples, upon deprotonation of the complex, the electron density at the $\mathrm{N}-\mathrm{Be}$ and $\mathrm{N}-\mathrm{B}$ BCPs increases by 0.034 and 0.039 a.u., respectively. Consistently, the $\mathrm{N}-\mathrm{Be}$ and the $\mathrm{N}-\mathrm{B}$ Wiberg bond orders also increase from 0.259 to 0.526 for the $\mathrm{BeH}_{2}$ containing complex and from 0.572 to 0.739 for the $\mathrm{BH}_{3}$ containing one.

Table 2 Acidity enhancement, $\Delta \Delta_{\text {acid }} G^{0}$, and stabilization free energies of neutral, $\Delta_{\mathrm{r}} G_{1}{ }^{0}$, and deprotonated species, $\Delta_{\mathrm{r}} G_{3}{ }^{0}$, when $\mathrm{R}-\mathrm{XH}_{2}(\mathrm{R}=$ ethyl, vinyl, ethynyl; $X=N, P, A s, S b$ ) bases interact with $\mathrm{BeH}_{2}$ or $\mathrm{BH}_{3}$. All values in $\mathrm{kJ} \mathrm{mol}^{-1}$

\begin{tabular}{|c|c|c|c|c|c|c|}
\hline & \multicolumn{2}{|c|}{$\left(\Delta \Delta_{\mathrm{acid}} G^{0}\right)^{a}$} & \multicolumn{2}{|l|}{$\Delta_{\mathrm{r}} G_{1}{ }^{0}$} & \multicolumn{2}{|l|}{$\Delta_{\mathrm{r}} G_{3}^{0}$} \\
\hline & $\mathrm{Y}=\mathrm{BeH}_{2}$ & $\mathrm{Y}=\mathrm{BH}_{3}$ & $\mathrm{Y}=\mathrm{BeH}_{2}$ & $\mathrm{Y}=\mathrm{BH}_{3}$ & $\mathrm{Y}=\mathrm{BeH}_{2}$ & $\mathrm{Y}=\mathrm{BH}_{3}$ \\
\hline \multicolumn{7}{|l|}{$\mathrm{R}=$ Ethyl } \\
\hline $\mathrm{X}=\mathrm{N}$ & 226 & 179 & -59 & -74 & -285 & -253 \\
\hline $\mathrm{X}=\mathrm{P}$ & 139 & 113 & -12 & -64 & -151 & -177 \\
\hline $\mathrm{X}=\mathrm{As}$ & 117 & 99 & -17 & -54 & -134 & -153 \\
\hline $\mathrm{X}=\mathrm{Sb}$ & 121 & 119 & +17 & -20 & -105 & -139 \\
\hline \multicolumn{7}{|c|}{$\mathrm{R}=$ Vinyl } \\
\hline $\mathrm{X}=\mathrm{N}$ & 208 & 171 & -29 & -41 & -237 & -212 \\
\hline $\mathrm{X}=\mathrm{P}$ & 124 & 78 & $-2[-11]^{b}$ & -65 & -126 & -143 \\
\hline $\mathrm{X}=\mathrm{As}$ & 124 & 102 & $+13[-2]^{b}$ & -24 & -111 & -126 \\
\hline $\mathrm{X}=\mathrm{Sb}$ & 114 & 106 & +17 & -15 & -97 & -121 \\
\hline \multicolumn{7}{|c|}{$\mathrm{R}=$ Ethynyl } \\
\hline $\mathrm{X}=\mathrm{N}$ & 190 & 152 & -7 & -16 & -197 & -168 \\
\hline $\mathrm{X}=\mathrm{P}$ & 125 & 93 & $+9[+1]^{b}$ & -43 & -116 & 136 \\
\hline $\mathrm{X}=\mathrm{As}$ & 127 & 106 & $+26[+9]^{b}$ & -11 & -101 & -117 \\
\hline $\mathrm{X}=\mathrm{Sb}$ & 108 & 110 & $+18[+17]^{c}$ & -7 & -90 & -117 \\
\hline
\end{tabular}

${ }^{a}$ These values measure the acidity enhancement upon $\mathrm{BeH}_{2}$ or $\mathrm{BH}_{3}$ association and are given by the difference $\Delta_{\mathrm{r}} G_{2}{ }^{0}-\Delta_{\mathrm{r}} G_{4}{ }^{0} \cdot{ }^{b}$ Values calculated at the G4 level of theory. ${ }^{c}$ Value calculated at the $\operatorname{CCSD}(\mathrm{T}) /$ Def-QZVP level of theory. 


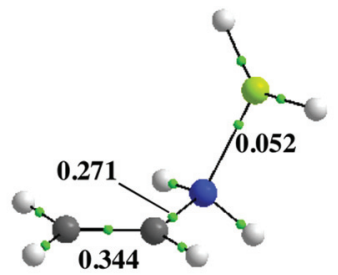

$\mathrm{CH}_{2}=\mathrm{CHNH}_{2} \mathrm{BeH}_{2}$

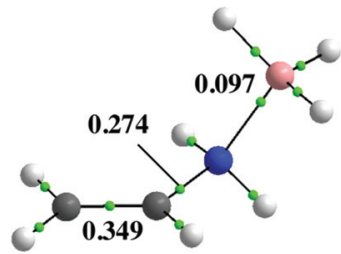

$\mathrm{CH}_{2}=\mathrm{CHNH}_{2} \mathrm{BH}_{3}$

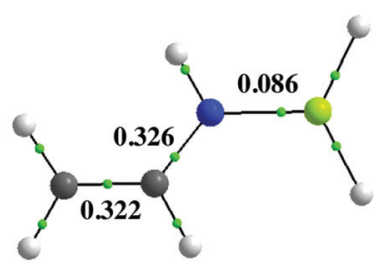

$\left[\mathrm{CH}_{2}=\mathrm{CHNHBeH}_{2}\right]^{-}$

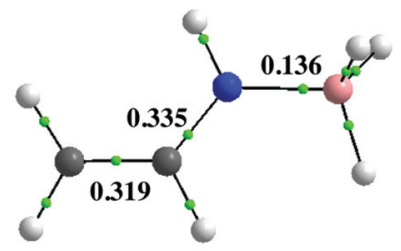

$\left[\mathrm{CH}_{2}=\mathrm{CHNHBH}_{3}\right]^{-}$
Fig. 1 Molecular graphs of the $\mathrm{BeH}_{2}$ and $\mathrm{BH}_{3}$ complexes with vinylamine and their corresponding anionic deprotonated species. Green dots denote BCPs. Electron densities are in a.u.

Consistently, the LMO-EDA also shows that for both the $\mathrm{BeH}_{2}$ and the $\mathrm{BH}_{3}$ complexes the interaction energies between the two subunits are very large, but more than three times larger for the corresponding deprotonated species, as shown in Table 3 for the ethynyl derivatives. Similar results are obtained for the vinyl analogues (see Table S2 of the ESI $\dagger$ ).

It is also worth noting that the most significant contributions to the interaction energy come from the electrostatic and polarization terms, whereas dispersion is marginal. The former results are expected taking into account that the direct interaction involves a negatively charged basic site and a

Table 3 LMO-EDA partition terms $\left(\mathrm{kJ} \mathrm{mol}^{-1}\right)$ for the complexes formed by association of $\mathrm{CH} \equiv \mathrm{CXH}_{2}$ and its deprotonated anions with $\mathrm{BeH}_{2}$ and $\mathrm{BH}_{3}$

\begin{tabular}{|c|c|c|c|c|c|}
\hline Complex & $E_{\text {int }}$ & $\Delta E_{\text {elstat }}$ & $\Delta E_{\text {ex+rep. }}$ & $\Delta E_{\text {pol. }}$ & $\Delta E_{\text {disp }}$ \\
\hline \multicolumn{6}{|c|}{$\mathrm{CH} \equiv \mathrm{CXH}_{2}: \mathrm{BeH}_{2}$} \\
\hline $\mathrm{X}=\mathrm{N}$ & -83 & -172 & 207 & -110 & -8 \\
\hline$X=P$ & -53 & -114 & 175 & -109 & -5 \\
\hline $\mathrm{X}=\mathrm{As}$ & -32 & -81 & 135 & -81 & -5 \\
\hline \multicolumn{6}{|c|}{$\left[\mathrm{CH} \equiv \mathrm{CXH}: \mathrm{BeH}_{2}\right]^{-}$} \\
\hline $\mathrm{X}=\mathrm{N}$ & -318 & -384 & 312 & -240 & -6 \\
\hline $\mathrm{X}=\mathrm{P}$ & -216 & -256 & 252 & -206 & -6 \\
\hline $\mathrm{X}=\mathrm{As}$ & -198 & -241 & 243 & -194 & -6 \\
\hline \multicolumn{6}{|c|}{$\mathrm{CH} \equiv \mathrm{CXH}_{2}: \mathrm{BH}_{3}$} \\
\hline $\mathrm{X}=\mathrm{N}$ & -119 & -247 & 386 & -247 & -11 \\
\hline $\mathrm{X}=\mathrm{P}$ & -143 & -247 & 483 & -370 & -9 \\
\hline $\mathrm{X}=\mathrm{As}$ & -99 & -190 & 381 & -282 & -8 \\
\hline \multicolumn{6}{|c|}{$\left[\mathrm{CH} \equiv \mathrm{CXH}: \mathrm{BH}_{3}\right]^{-}$} \\
\hline $\mathrm{X}=\mathrm{N}$ & -306 & -410 & 553 & -441 & -8 \\
\hline $\mathrm{X}=\mathrm{P}$ & -258 & -312 & 501 & -437 & -10 \\
\hline $\mathrm{X}=\mathrm{As}$ & -233 & -291 & 466 & -398 & -10 \\
\hline
\end{tabular}

highly positively charged acidic site. The large values of the polarization contributions are associated with significant charge donations from the unsaturated compound to the empty orbitals of the Lewis acid as shown by the NOCV analysis. For the $\mathrm{CH} \equiv \mathrm{CNH}_{2}: \mathrm{BeH}_{2}$ and $\mathrm{CH} \equiv \mathrm{CNH}_{2}: \mathrm{BH}_{3}$ complexes, taken as suitable examples, the main donation takes place from the $\mathrm{N}$ lone pair of the amine to the empty p orbital of the Be or B atom, accounting for orbital interaction energies of 94 and $222 \mathrm{~kJ} \mathrm{~mol}^{-1}$, respectively. In both cases also a very small back-donation from the $\mathrm{Be}-\mathrm{H}(\mathrm{B}-\mathrm{H})$ bonding orbitals towards the $\pi_{\mathrm{CC}^{*}}$ antibonding orbital is observed, accounting for additional orbital interaction energies of 8 and $20 \mathrm{~kJ} \mathrm{~mol}^{-1}$. For the corresponding deprotonated complexes, namely $\left[\mathrm{CH} \equiv \mathrm{CNH}: \mathrm{BeH}_{2}\right]^{-}$and $\left[\mathrm{CH} \equiv \mathrm{CNH}: \mathrm{BH}_{3}\right]^{-}$, the aforementioned charge donations become much stronger, with interaction energies of 151 and $355 \mathrm{~kJ} \mathrm{~mol}^{-1}$, as well as the backdonations, with interaction energies of $37 \mathrm{~kJ} \mathrm{~mol}^{-1}$ for the $\mathrm{BeH}_{2}$ complexes, and $46 \mathrm{~kJ} \mathrm{~mol}^{-1}$ for the $\mathrm{BH}_{3}$ complexes. On top of that, for both systems, there is a second charge donation also from the bonding $\pi_{\mathrm{CC}}$ to the antibonding $\sigma_{\mathrm{BeH}}{ }^{*}$ or $\sigma_{\mathrm{BH}}{ }^{*}$ orbitals, which accounts for an additional interaction energy of the order of $40 \mathrm{~kJ} \mathrm{~mol}^{-1}$.

It is worth noting that the calculated acidity enhancement (first two columns of Table 2) is systematically larger when the Lewis acid is $\mathrm{BeH}_{2}$. Note however, that in general, the stabilization of both the neutral base and its deprotonated form is larger when the Lewis acid is $\mathrm{BH}_{3}$ than when it is $\mathrm{BeH}_{2}$. Therefore, the larger acidity enhancement observed for $\mathrm{BeH}_{2}$ complexes comes from a larger difference between $\Delta_{\mathrm{r}} G_{1}{ }^{0}$ and $\Delta_{\mathrm{r}} G_{3}{ }^{0}$ even though each individual value is smaller than for $\mathrm{BH}_{3}$, implying that the extra-stabilization of the anion is larger in relative terms when the Lewis acid is $\mathrm{BeH}_{2}$. This is in harmony with the interaction energies (see Table 3) and the electron densities (see Fig. 1). Indeed, from the values in Table 3, whereas the interaction energy for the $\mathrm{BeH}_{2}$ complexes increases $c a .280 \%$ upon deprotonation, for the $\mathrm{BH}_{3}$ analogues this increase is of only $c a .160 \%$. Similarly, whereas the electron density at the N-Be BCP increases $65 \%$ upon deprotonation of the complex, that at the N-B BCP only increases by $40 \%$.

There are other subtle differences between both series of data. While for the $\mathrm{BH}_{3}$ complexes the value of $\Delta_{\mathrm{r}} G_{1}{ }^{0}$ is always negative, i.e. the neutral compound is always stabilized by association with borane, this is not necessarily the case upon association with $\mathrm{BeH}_{2}$. In principle, as shown in Table 2, the formation of $\mathrm{BeH}_{2}$ complexes for ethylstibine, vinylarsine, vinylstibine, ethynylphosphine, ethynylarsine and ethynylstibine is predicted to be an endergonic process, even though it is exothermic in terms of enthalpies. Since the reaction freeenergies are rather small, we decided to verify whether these predictions could be an artifact of the DFT approach used, so for the $\mathrm{P}$ and As containing complexes the values of $\Delta_{\mathrm{r}} G_{1}{ }^{0}$ were re-evaluated at the G4 level. For the Sb containing compounds, for which the G4 procedure is not available, the $a b$ initio reference calculations were carried out at the $\operatorname{CCSD}(\mathrm{T}) /$ Def2-QZVP level of theory. These high-level ab initio 
values showed that, although the B3LYP method slightly underestimates the stability of the neutral $\mathrm{BeH}_{2}$ complexes, the formation of the complexes of $\mathrm{BeH}_{2}$ with ethynylarsine and ethynylstibine is indeed slightly endergonic. This made us explore the relative stability of complexes in which $\mathrm{BeH}_{2}$ interacts with the double or triple CC bond rather than with the heteroatom (see Fig. 2).

This survey, carried out at the G4 level, showed that the global minimum for the interaction between both
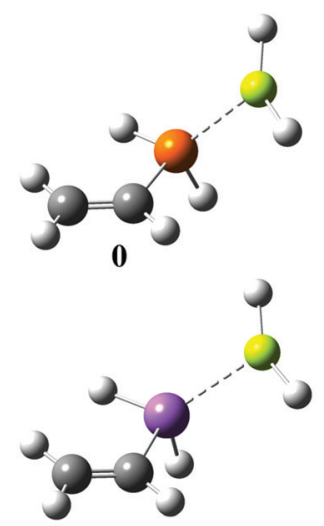

0

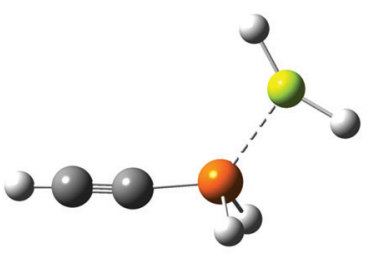

0

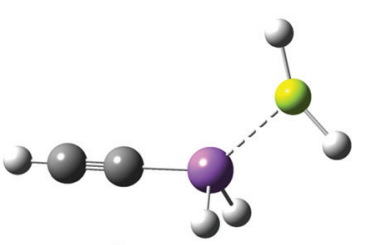

0

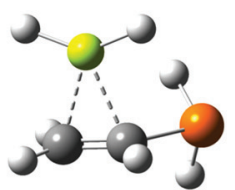

29

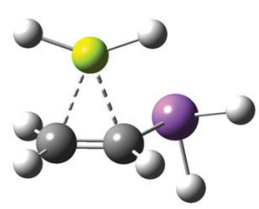

13

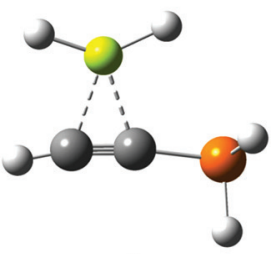

$-4$

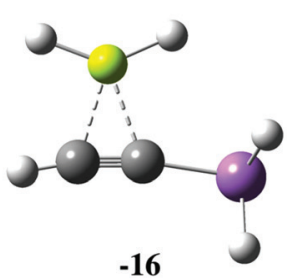

$-16$
Fig. 2 G4 relative stabilities $\left(\mathrm{kJ} \mathrm{mol}^{-1}\right)$ for the more stable conformations of complexes of $\mathrm{BeH}_{2}$ with vinyl- and ethynyl phosphine and arsine, showing that for ethynyl the $\pi$-type complex is the most stable. ethynylphosphine or ethynylarsine and $\mathrm{BeH}_{2}$ corresponds to a $\pi$-type complex, which was found to be 4 and $16 \mathrm{~kJ} \mathrm{~mol}^{-1}$ lower in free energy than the complex in which $\mathrm{BeH}_{2}$ interacts with the $\mathrm{P}$ or the As atom, respectively. However, a similar survey for the complexes involving the analogous vinyl derivatives showed that always the complex in which $\mathrm{BeH}_{2}$ is directly attached to the heteroatom is more stable than the $\pi$-complex (29 $\mathrm{kJ} \mathrm{mol}^{-1}$ for $\mathrm{P}$ and $13 \mathrm{~kJ} \mathrm{~mol}^{-1}$ for As). These findings are consistent with studies that showed that for some fluxional beryllium allyl complexes, recently synthesized, both $\sigma$ - and $\pi$-bound forms would be potential energy minima. ${ }^{54}$

It is worth noting that although for $\mathrm{BH}_{3}$ containing complexes the value of $\Delta_{\mathrm{r}} G_{1}{ }^{0}$ for the ethynyl containing systems is smaller in absolute value than for the vinyl containing analogues, in all cases the formation of the complexes is predicted to be exergonic.

\section{Acidity trends}

Besides the acidity enhancement discussed above, the complexation also results in a change in the acidity trends. Whereas, as we have indicated before, the acidity of the free compounds increases down the group, the values of $\Delta_{\text {acid }} G^{0}$, for both the $\mathrm{BeH}_{2}$ and the $\mathrm{BH}_{3}$ complexes, present a maximum (minimum acidity) for the vinyl and the ethynyl phosphine (see Fig. 3).

Why the complexes of vinyl- and ethynyl-phosphine are less acidic than the corresponding amine complexes can be understood by comparing the bonding patterns exhibited by the corresponding neutral and deprotonated systems. For this purpose we present in Fig. 4 the molecular graphs of the $\mathrm{BeH}_{2}$ complexes of vinyl and ethynyl-amine and their deprotonated species as compared with those of the phosphine containing analogues. These molecular graphs denote already some differences between the structures of vinylamine: $\mathrm{BeH}_{2}$ and vinylphosphine : $\mathrm{BeH}_{2}$ complexes. In the latter the $\mathrm{BeH}_{2}$ Lewis acid lies in the same plane as the $\mathrm{C}=\mathrm{C}$ double bond favoring the formation of a dihydrogen bond between one of the $\mathrm{H}$ atoms of the beryllium dihydride (negatively charged) and one of the $\mathrm{H}$ atoms of the unsaturated moiety (positively charged). This is not the case, however, for the vinylamine: $\mathrm{BeH}_{2}$ complex where the $\mathrm{BeH}_{2}$ group is out of the $\mathrm{C}=\mathrm{C}$ plane.

However, the most dramatic differences are observed when comparing the deprotonated anionic complexes. For the
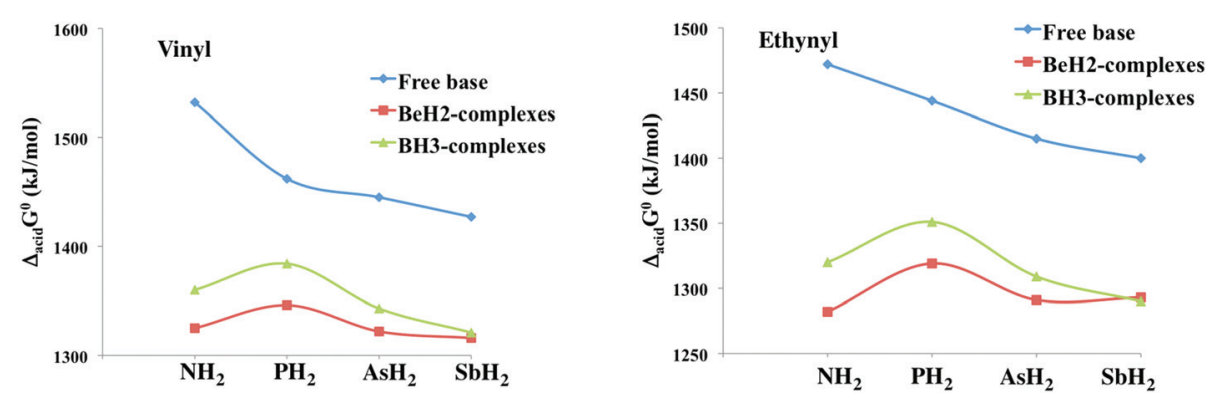

Fig. 3 Variation of the intrinsic acidities of $\mathrm{R}-\mathrm{XH}_{2}(\mathrm{R}=$ vinyl, ethynyl; $\mathrm{X}=\mathrm{N}, \mathrm{P}, \mathrm{As}, \mathrm{Sb})$ compounds and of their $\mathrm{R}-\mathrm{XH}_{2}: \mathrm{Y}\left(\mathrm{Y}=\mathrm{BeH} \mathrm{H}_{2}, \mathrm{BH}\right) \mathrm{complexes}$. 

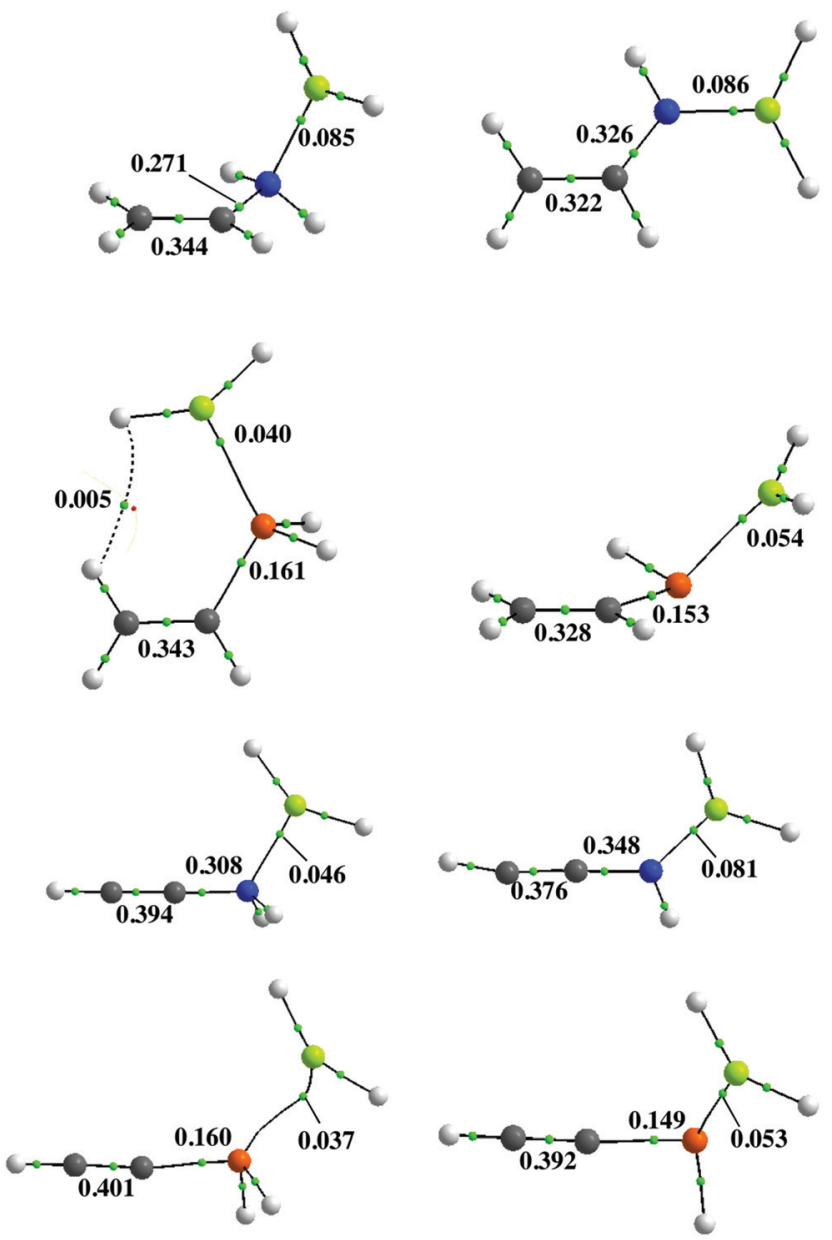

Fig. 4 Molecular graphs of the $\mathrm{BeH}_{2}$ complexes with vinyl- and ethynyl-amine and vinyl- and ethynyl-phosphine, and their corresponding anionic deprotonated species. Green dots denote BCPs. Electron densities are in a.u.

amines, the $\mathrm{BeH}_{2}$ molecule now lies in the same plane as the $\mathrm{C}=\mathrm{C}$ bond in the vinyl derivative and in the same plane as the $\mathrm{CCNH}$ group in the ethynyl derivative, whereas for the phosphorous containing complexes the $\mathrm{BeH}_{2}$ lies always in a different plane from the one containing the double bond or the CCPH moiety. These geometrical rearrangements point to the existence of a strong conjugation of the amino group with the $\pi$-system of the unsaturated moiety, which is not observed for the phosphines. Several features ratify this. The electron density at the $\mathrm{C}-\mathrm{N}$ BCP increases dramatically (from 0.271 to 0.326 a.u. in the vinyl complex and from 0.308 to 0.348 a.u. in the ethynyl complex) on going from the neutral to the deprotonated form. Concomitantly, the $\mathrm{C}-\mathrm{N}$ bond lengths become shorter by $0.08 \AA$ in the vinyl case and by $0.06 \AA$ in the ethynyl one. The NBO analysis also shows a significant increase in the Wiberg bond order of the $\mathrm{C}-\mathrm{N}$ (from 1.02 to 1.28 in the vinylamine complex and from 1.05 to 1.30 in the ethynylamine complex) on going from the neutral to the deprotonated complexes. As expected, the conjugation of the $\mathrm{N}$ lone pair with the CC $\pi$-system necessarily implies a decrease of the double and triple bond character of the $\mathrm{C}-\mathrm{C}$ bonds of the vinyl and the ethynyl moieties, which in the first case is mirrored in a lengthening of the $\mathrm{C}=\mathrm{C}$ bond from 1.332 to $1.366 \AA$. For ethynyl, not only the $\mathrm{C} \equiv \mathrm{C}$ bond lengthens from 1.205 to $1.231 \AA$ but the HCC fragment is not linear anymore, the HCC angle being $159^{\circ}$, showing the significant change in the hybridization of the carbon atoms of the unsaturated moiety. Conversely, for the complexes involving vinylphosphine and ethynylphosphine, the behavior observed is just the opposite. In the first place the $\mathrm{PH}_{2}$ is situated in a different plane from the unsaturated moiety, which does not favor conjugation, and on going from the neutral to the deprotonated species, in both vinyl and ethynyl complexes, the $\mathrm{C}-\mathrm{P}$ bond becomes weaker. Indeed, the electron density at the $\mathrm{C}-\mathrm{P}$ BCP decreases from 0.161 to $0.153 \mathrm{a}$.u. for vinyl and from 0.160 to $0.149 \mathrm{a}$.u. for ethynyl, and the C-P bond becomes longer ( $c a$. $0.01 \AA$ ). The same kind of behavior is also observed for the analogue complexes with $\mathrm{BH}_{3}$. All these results indicate that the $\mathrm{N}$ containing anions become much more stabilized in relative terms than the $\mathrm{P}$ containing ones, what should result in a much larger increase in the acidity for the amines than for the phosphines, explaining the appearance of the maxima in Fig. 3. Why the conjugation is favored in amines is a well known mechanism related to the efficiency of the overlap between the lone pairs of the heteroatom and the $\pi$-system when the heteroatom belongs to the first row.

\section{Active center for deprotonation}

In our previous discussion it was implicitly assumed that for the complexes between $\mathrm{BeH}_{2}$ or $\mathrm{BH}_{3}$ and $\mathrm{H}_{2} \mathrm{C}=\mathrm{CHXH}_{2}$ or $\mathrm{HC} \equiv \mathrm{CXH}_{2}(\mathrm{X}=\mathrm{N}, \mathrm{P}, \mathrm{As}, \mathrm{Sb})$, the lost proton would always come from the $\mathrm{XH}_{2}$ group, as has been shown to be the case for different phosphine-boranes ${ }^{30}$ and amine-boranes ${ }^{32}$ as well as for similar complexes with $\mathrm{BeH}_{2}$ derivatives. ${ }^{34}$ However, when dealing with the unsaturated systems we found, in particular for the ethynyl- $\mathrm{BeH}_{2}$ complexes, that when optimizing the species deprotonated at the $\mathrm{BeH}_{2}$, the process yields structures in which the $\mathrm{BeH}$ group inserts into the $\mathrm{C}-\mathrm{X}(\mathrm{X}=\mathrm{P}, \mathrm{As}$, $\mathrm{Sb}$ ) bond. A further analysis showed that all deprotonated structures in which $\mathrm{BeH}$ or $\mathrm{BH}_{2}$ appears inserted into the $\mathrm{C}-\mathrm{X}$ bond are more stable than the conventional ones in which the proton departs from the $\mathrm{XH}_{2}$ group, with the only exception of vinylamine (see Fig. 5).

To understand the enhanced stability of the Be or B deprotonated complexes let us take the couples $\left[\mathrm{CH}_{2}=\mathrm{CHPH}-\right.$ $\left.\mathrm{BH}_{3}\right]^{-} /\left[\mathrm{CH}_{2}=\mathrm{CHBH}_{2}-\mathrm{PH}_{2}\right]^{-}$and $\left[\mathrm{CH} \equiv \mathrm{CPH}-\mathrm{BH}_{3}\right]^{-} /$ $\left[\mathrm{CH} \equiv \mathrm{CBH}_{2}-\mathrm{PH}_{2}\right]^{-}$as suitable examples. Since the two complexes involved in each couple have the same unsaturated moiety, the different stability of the two forms should come essentially from the differences arising when a $\mathrm{C}-\mathrm{PH}$ bond is replaced by a $\mathrm{C}-\mathrm{BH}_{2}$ and when a $\mathrm{P}-\mathrm{BH}_{3}$ is replaced by a $\mathrm{P}-\mathrm{BH}_{2}$. These differences have been estimated by calculating the LMO-EDA interaction energies between the fragments resulting from the bond fissions as indicated in Fig. 6 .

It is apparent that whereas the interaction energies between $\mathrm{CH}_{2} \mathrm{CH}$ (or $\mathrm{CHC}$ ) and $\mathrm{PHBH}_{3}$ and between $\mathrm{CH}_{2} \mathrm{CH}$ (or $\mathrm{CHC}$ ) 


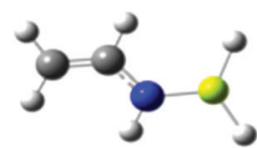

$\mathbf{0}$

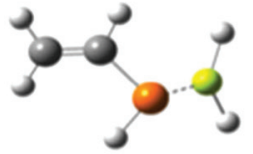

$\mathbf{0}$
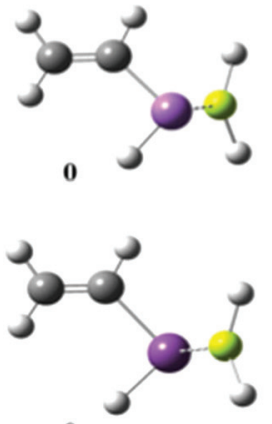

0
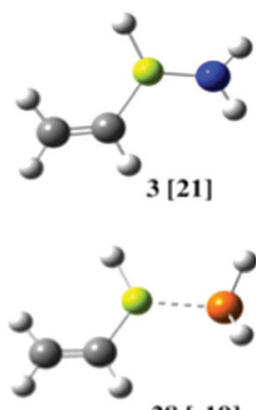

$-28[-19]$
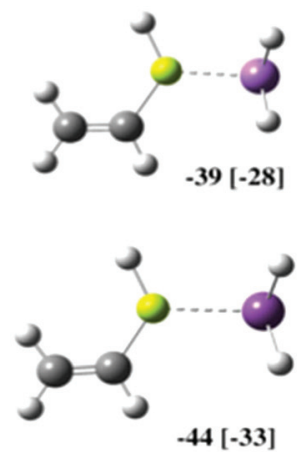
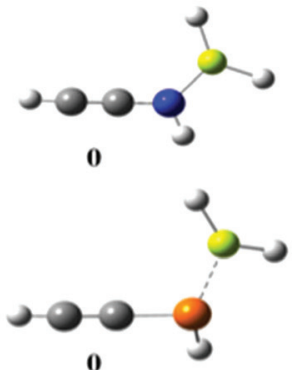

$\mathbf{0}$
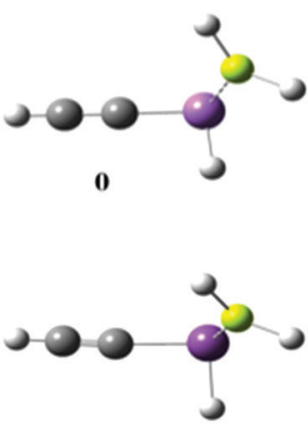

0
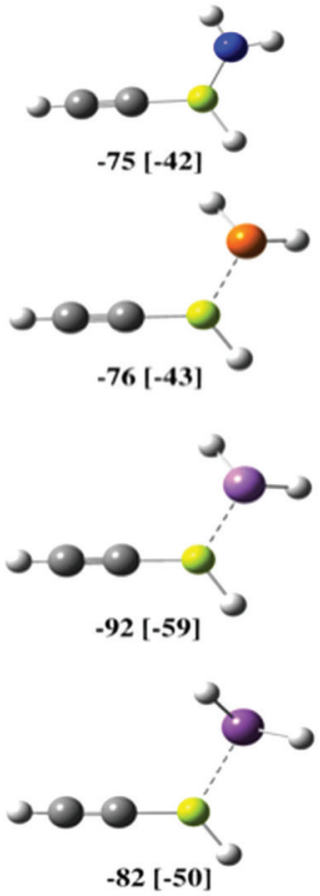

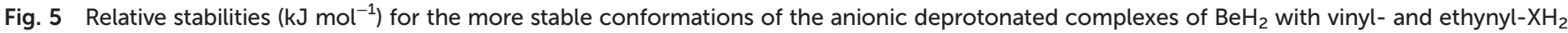

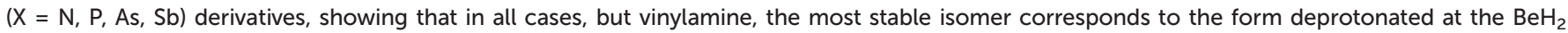

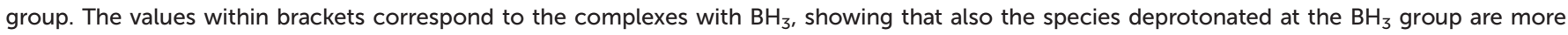
stable than those deprotonated at the $\mathrm{XH}_{2}$ group.

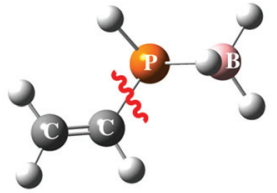

711

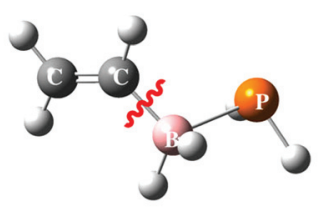

667

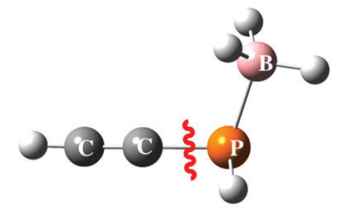

869

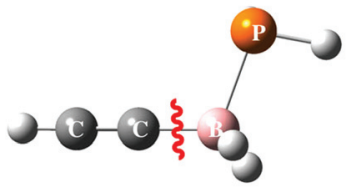

862

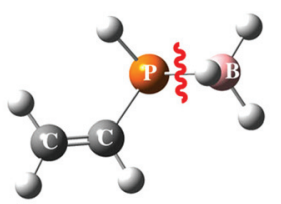

271

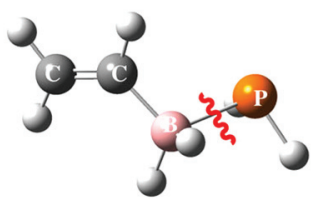

451

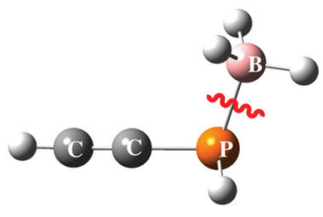

268

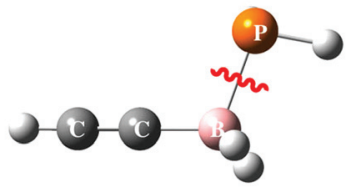

463
Fig. 6 LMO-EDA interaction energies $\left(\mathrm{kJ} \mathrm{mol}^{-1}\right)$ between the fragments resulting from the bond fissions indicated by the wiggled red line. and $\mathrm{BH}_{2} \mathrm{PH}_{2}$ are rather similar, the interaction energy between $\mathrm{CH}_{2} \mathrm{CHBH}_{2}$ (or $\mathrm{CHCBH}_{2}$ ) and the $\mathrm{PH}_{2}$ group is much larger than that between $\mathrm{CH}_{2} \mathrm{CHPH}$ (or $\mathrm{CHCPH}$ ) and $\mathrm{BH}_{3}$. Hence, we can conclude that $\mathrm{B}$ prefers being di-coordinated to both $\mathrm{C}$ and the heteroatom ( $\mathrm{P}$ in our example) than only to the heteroatom, due to its high electron deficient character. Thus, the $\mathrm{B}$ deprotonated species becomes much more stable than those deprotonated at the heteroatom. Similar results are found for the corresponding complexes involving $\mathrm{BeH}_{2}$ rather than $\mathrm{BH}_{3}$ (see Fig. S1 of the $\mathrm{ESI}_{\dagger} \dagger$ ).

A final question that needs to be addressed is the feasibility of the formation of the $\left[\mathrm{HCC}-\mathrm{Y}-\mathrm{XH}_{2}\right]^{-}$and $\left[\mathrm{H}_{2} \mathrm{CCH}-\mathrm{Y}-\mathrm{XH}_{2}\right]^{-}$ ( $\mathrm{Y}=\mathrm{BH}_{2}, \mathrm{BeH} ; \mathrm{X}=\mathrm{N}, \mathrm{P}, \mathrm{As}, \mathrm{Sb}$ ) complexes. Two mechanisms are in principle possibly depending on whether the insertion of the $\mathrm{Y}$ group into the $\mathrm{C}-\mathrm{X}$ bond takes place before or after deprotonation of the complex. These possibilities were explored using $\mathrm{HC} \equiv \mathrm{C}-\mathrm{AsH}_{2}: \mathrm{BH}_{3}$ and $\mathrm{HC} \equiv \mathrm{C}-\mathrm{AsH}_{2}: \mathrm{BeH}_{2}$ as suitable benchmark cases. As shown in Fig. 7a and 7b, the first step for the insertion before deprotonation corresponds to the formation of the $\pi$-complex $\mathbf{B}$, which is followed by a proton transfer from the $\mathrm{BH}_{3}$ group towards the $\mathrm{AsH}_{2}$ one to yield complex C. From here the insertion of the $\mathrm{BH}_{2}$ group into the C-As bond takes place through the TS_CD transition state. The subsequent deprotonation of the $\mathrm{AsH}_{3}$ group yields the most stable $\left[\mathrm{HCC}-\mathrm{BH}_{2}-\mathrm{AsH}_{2}\right]^{-}$deprotonated form $\mathbf{D}^{-}$. It should be noted that the mechanisms are similar for both $\mathrm{BH}_{3}$ and $\mathrm{BeH}_{2}$, although for the latter the $\pi$-complex $\mathbf{B}$ is more stable than adduct A. However, in both cases the energy bar- 

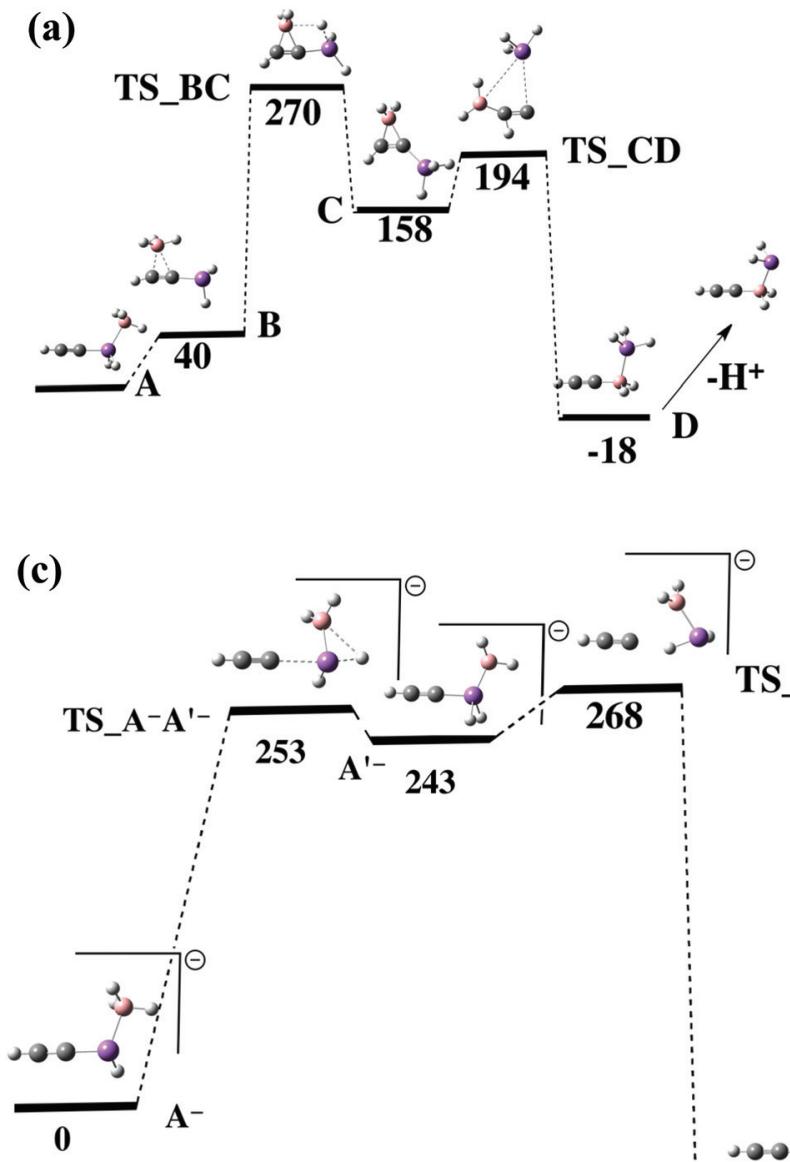

(b)

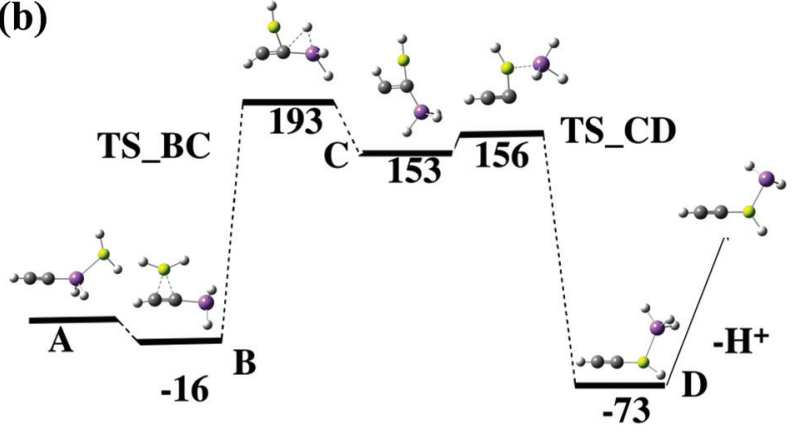

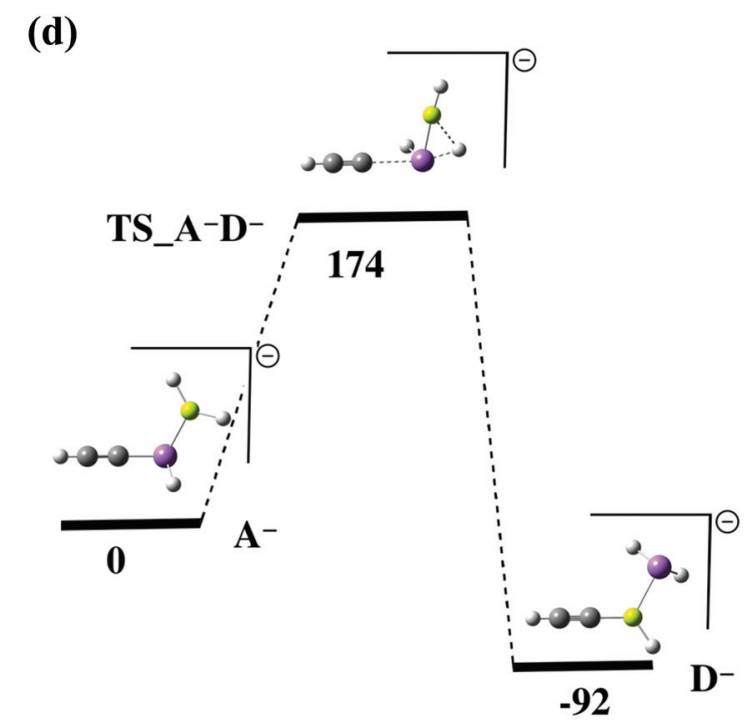

Fig. 7 Energy profiles ( $\left(\mathrm{KJ} \mathrm{mol}^{-1}\right.$ ) for: (a) and (b) the insertion mechanisms that connect the $\mathrm{HCCAsH}_{2}-\mathrm{BH}_{3}$ and $\mathrm{HCCAsH}_{2}-\mathrm{BeH}_{2}$ complexes with the insertion isomers, $\mathrm{HCCBH}_{2}-\mathrm{AsH}_{3}$ and $\mathrm{HCCBeH}-\mathrm{AsH}_{3}$, as precursors of the $\left[\mathrm{HCCBH}_{2}-\mathrm{AsH}_{2}\right]^{-}$and $\left[\mathrm{HCCBeH}-\mathrm{AsH}_{2}\right]^{-}$deprotonated species, respectively; (c) and (d) the proton transfer process with the origin in the As deprotonated species $\left(\mathrm{A}^{-}\right)\left[\mathrm{HCC}-\mathrm{AsH}_{-} \mathrm{BH}\right]^{-}$and $\left[\mathrm{HCC}-\mathrm{AsH}_{-} \mathrm{BeH}_{2}\right]^{-}$. In mechanism (c) an $\left[\mathrm{HCC}-\mathrm{AsH}_{2}-\mathrm{BH}_{2}\right]^{-}\left(\mathrm{A}^{-}\right)$isomer is produced, which further isomerizes to yield form $\mathbf{D}^{-}$whereas in (d) this latter form is directly produced because the insertion of the $\mathrm{BeH}$ group into the $\mathrm{C}$-As bond takes place concomitantly with the proton transfer.

riers involved are high enough to likely prevent these processes in the gas phase. Similar mechanisms are found for the vinyl derivatives and other heteroatoms (see Fig. S2a-c of the ESI $\dagger$ ).

If the insertion mechanism takes place after the deprotonation of the system, the first step from the As deprotonated form, $\mathbf{A}^{-}$, corresponds to a $\mathrm{H}$ shift from the $\mathrm{BH}_{3}$ or the $\mathrm{BeH}_{2}$ group towards the AsH one (see Fig. 7c and 7d). However, in this case there is a significant difference between $\mathrm{BH}_{3}$ and $\mathrm{BeH}_{2}$. Whereas in the first case the hydrogen shift produces an intermediate isomer $\left[\mathrm{HCC}-\mathrm{AsH}_{2}-\mathrm{BH}_{2}\right]^{-}\left(\mathbf{A}^{\prime-}\right)$, which finally isomerizes, through $\mathbf{T S} \mathbf{A}^{\prime-} \mathbf{D}^{-}$, to yield the most stable anion [HCC- $\left.\mathrm{BH}_{2}-\mathrm{AsH}_{2}\right]^{-}\left(\mathbf{D}^{-}\right)$, for $\mathrm{BeH}_{2}$ the $\mathrm{H}$ transfer is concomitant with the insertion of the $\mathrm{BeH}$ group into the $\mathrm{C}-\mathrm{As}$ bond, yielding directly the most stable [HCC-BeH-AsH $]^{-}$Be-depronated species, $\mathbf{D}^{-}$. This implies that, as mentioned above, for the ethynyl- $\mathrm{BeH}_{2}$ complexes the direct deprotonation of the $\mathrm{BeH}_{2}$ group leads to the $\left[\mathrm{HCC}-\mathrm{BeH}-\mathrm{AsH}_{2}\right]^{-}\left(\mathbf{D}^{-}\right)$anion in a barrierless process. We have verified, however, that this is not the case, for the corresponding amine, for the vinyl-derivatives, or when the Lewis acid is borane, where the insertion process requires a rather high activation barrier.

The obvious consequence is that the acidity enhancement for the ethynyl P, As and Sb containing derivatives is actually much larger than expected from the values reported in Tables 1 and 2 . Hence, in general the complexes of the ethynyl derivatives with $\mathrm{BeH}_{2}$ are between 75 and $92 \mathrm{~kJ} \mathrm{~mol}^{-1}$ more acidic than expected if the deprotonation would take place at the $\mathrm{BeH}_{2}$ group. The important implication is that the complexes between ethynylarsine and ethynylstibine with $\mathrm{BeH}_{2}$ are predicted to be Be acids $\left(\Delta_{\text {acid }} G^{0}=1206\right.$ and $1211 \mathrm{~kJ} \mathrm{~mol}^{-1}$, respectively) as acidic as perchloric acid $\left(\Delta_{\text {acid }} G^{0}=1200 \pm 50 \mathrm{~kJ}\right.$ $\left.\mathrm{mol}^{-1}\right) !^{55}$

\section{Conclusions}

The intrinsic acidity of the unsaturated vinyl- and ethynylamines, phosphines, arsines and stibines is systematically 
larger than that of the saturated ethyl analogues, reflecting the larger electronegativity of the vinyl and ethynyl groups with respect to the ethyl one. For the free systems a steady increase of this intrinsic acidity down the group is observed no matter the nature of the organic moiety to which the $\mathrm{XH}_{2}(\mathrm{X}=\mathrm{N}, \mathrm{P}$, $\mathrm{As}, \mathrm{Sb}$ ) acidic site is bound. The association with both beryllium dihydride and borane leads to a dramatic acidity enhancement due to a much larger stabilization of the deprotonated anion than the neutral molecule. This acidity enhancement is larger for $\mathrm{BeH}_{2}$ than for $\mathrm{BH}_{3}$ complexes, and for the unsaturated compounds, it is accompanied by a change in the acidity trends, which do not steadily increase down the group, as for the free systems, but present a minimum for both the vinyl- and the ethynyl-phosphine. This unexpected result is due to a much larger increase of the acidity of $\mathrm{N}$ containing systems, due to the ability of the $\mathrm{N}$ to conjugate with the $\pi$-system in the anionic deprotonated species. Although $\mathrm{BeH}_{2}$ and $\mathrm{BH}_{3}$ complexes exhibit a rather similar behavior, there are subtle differences between both series of systems. When the molecule acting as a Lewis acid is beryllium dihydride, the $\pi$-type complexes in which the $\mathrm{BeH}_{2}$ molecules interact with the double or triple bond are found, in some cases, to be more stable, in terms of free energies, that the conventional complexes in which the attachment takes place at the heteroatom, $\mathrm{X}$. The most important finding, however, is that $\mathrm{P}, \mathrm{As}$, and $\mathrm{Sb}$ ethynyl complexes with $\mathrm{BeH}_{2}$ do not behave as $\mathrm{P}$, As, or $\mathrm{Sb}$ Brønsted acids, but unexpectedly as Be acids.

\section{Acknowledgements}

This work was partially supported by the Ministerio de Economía y Competitividad (project no. CTQ2012-35513-C02-01), by the CMST COST Action CM1204, and by the Project MADRISOLAR2, Ref.: S2009PPQ/1533 of the Comunidad Autónoma de Madrid. AMS acknowledges a FPI contract from the Ministerio de Economía y Competitividad of Spain. The computational time at Centro de Computación Científica (CCC) of Universidad Autónoma de Madrid is also acknowledged.

\section{References}

1 R. C. Taylor, Adv. Chem., 1964, 42, 59-10.

2 J. W. Dawson and K. Niedenzu, Boron-Nitrogen Compounds, Academic Press, New York, 1965.

3 B. Swanson, D. F. Shriver and J. A. Ibers, Inorg. Chem., 1969, 8, 2182-2189.

4 P. S. Bryan and R. L. Kuczkows, Inorg. Chem., 1971, 10, 200-201.

5 D. F. Shriver and B. Swanson, Inorg. Chem., 1971, 10, 13541360.

6 E. R. Lory and R. F. Porter, J. Am. Chem. Soc., 1973, 95, 1766-1770.

7 K. C. Janda, L. S. Bernstein, J. M. Steed, S. E. Novick and W. Klemperer, J. Am. Chem. Soc., 1978, 100, 8074-8079.
8 R. D. Suenram and L. R. Thorne, Chem. Phys. Lett., 1981, 78, 157-160.

9 N. N. Greenwood and A. Earnshaw, Chemistry of the Elements, Pergamon Press, Oxford, 1984.

10 A. C. Legon and H. E. Warner, J. Chem. Soc., Chem. Commun., 1991, 1397-1399.

11 P. Paetzold, Pure Appl. Chem., 1991, 63, 345-350.

12 M. A. Dvorak, R. S. Ford, R. D. Suenram, F. J. Lovas and K. R. Leopold, J. Am. Chem. Soc., 1992, 114, 108-115.

13 T. Brinck, J. S. Murray and P. Politzer, Inorg. Chem., 1993, 32, 2622-2625.

14 L. M. Nxumalo, M. Andrzejak and T. A. Ford, Vib. Spectrosc., 1996, 12, 221-235.

15 K. R. Leopold, Adv. Mol. Struct. Res., 1996, 2, 103-127.

16 H. Anane, A. Boutalib, I. Nebot-Gil and F. Tomas, J. Phys. Chem. A, 1998, 102, 7070-7073.

17 F. A. Cotton, G. Wilkinson, C. A. Murillo and M. Bochmann, Advanced Inorganic Chemistry, Wiley, New York, 1999.

18 S. Fau and G. Frenking, Mol. Phys., 1999, 96, 519-527.

19 G. Katzer, A. F. Sax and J. Kalcher, J. Phys. Chem. A, 1999, 103, 7894-7899.

20 B. D. Rowsell, F. J. Gillespie and G. L. Heard, Inorg. Chem., 1999, 38, 4659-4662.

21 R. Glaser, C. J. Horan, M. Lewis and H. Zollinger, J. Org. Chem., 1999, 64, 902-913.

22 F. Bessac and G. Frenking, Inorg. Chem., 2003, 42, 79907994.

23 J. A. Plumley and J. D. Evanseck, J. Phys. Chem. A, 2007, 111, 13472-13483.

24 M. Yáñez, P. Sanz, O. Mó, I. Alkorta and J. Elguero, J. Chem. Theor. Comput., 2009, 5, 2763-2771.

25 I. Alkorta, J. Elguero, J. E. Del Bene, O. Mo and M. Yanez, Chem. - Eur. J., 2010, 16, 11897-11905.

26 G. Sánchez-Sanz, I. Alkorta, J. Elguero, M. Yáñez and O. Mó, Phys. Chem. Chem. Phys., 2012, 14, 11468-11477.

27 A. Martín-Sómer, A. Lamsabhi, O. Mó and M. Yáñez, Comput. Theor. Chem., 2012, 998, 74-79.

28 J. H. Ren, C. J. Cramer and R. R. Squires, J. Am. Chem. Soc., 1999, 121, 2633-2634.

29 K. Dongsup and M. L. Klein, Chem. Phys. Lett., 1999, 308, 235-241.

30 M. Hurtado, M. Yáñez, R. Herrero, A. Guerrero, J. Z. Dávalos, J.-L. M. Abboud, B. Khater and J. C. Guillemin, Chem. - Eur. J., 2009, 15, 4622-4629.

31 A. Martín-Sómer, A. Lamsabhi, O. Mó and M. Yáñez, J. Phys. Chem. A, 2012, 116, 6950-6954.

32 A. Martín-Sómer, A. Lamsabhi, M. Yáñez, J. Z. Davalos, J. Gonzalez, R. Ramos and J. C. Guillemin, Chem. - Eur. J., 2012, 18, 15699-15705.

33 O. Mó, M. Yáñez, I. Alkorta and J. Elguero, J. Mol. Model, 2013, 19, 4139-4145.

34 M. Yáñez, O. Mó, I. Alkorta and J. Elguero, Chem. - Eur. J., 2013, 35, 11637-11643.

35 B. Khater, J.-C. Guillemin, A. Benidar, D. Begue and C. Pouchan, J. Chem. Phys., 2008, 129, 224308. 
36 B. Nemeth, B. Khater, T. Veszpremi and J.-C. Guillemin, Dalton Trans., 2009, 3526-3535.

37 M. P. Dressel, S. Nogai, R. J. F. Berger and H. Schmidbaur, Z. Naturforsch., B: Chem. Sci., 2003, 58, 173-182.

38 A. I. González, O. Mó, M. Yáñez, E. Leon, J. Tortajada, J. P. Morizur, I. Leito, P. C. Maria and J. F. Gal, J. Phys. Chem., 1996, 100, 10490-10496.

39 A. I. González, O. Mó and M. Yáñez, J. Phys. Chem. A, 1999, 103, 1662-1668.

40 L. A. Curtiss, P. C. Redfern and K. Raghavachari, J. Chem. Phys., 2007, 126, 12.

41 K. L. Schuchardt, B. T. Didier, T. Elsethagen, L. Sun, V. Gurumoorthi, J. Chase, J. Li and T. L. Windus, J. Chem. Inf. Model., 2007, 47, 1045-1052.

42 R. F. W. Bader, Atoms in Molecules. A Quantum Theory, Clarendon Press, Oxford, 1990.

43 C. F. Matta and R. J. Boyd, The Quantum Theory of Atoms in Molecules, Wiley-VCH, Weinheim, 2007.

44 A. E. Reed, L. A. Curtiss and F. Weinhold, Chem. Rev., 1988, 88, 899-926.

45 P. F. Su and H. Li, J. Chem. Phys., 2009, 131, 014102.

46 M. Mitoraj and A. Michalak, J. Mol. Model, 2007, 13, 347355.

47 K. B. Wiberg, Tetrahedron, 1968, 24, 1083-1088.

48 T. Ziegler and A. Rauk, Inorg. Chem., 1979, 18, 1755-1759.

49 G. te Velde, F. M. Bickelhaupt, E. J. Baerends, C. Fonseca Guerra, S. J. A. van Gisbergen, J. G. Snijders and T. Ziegler, J. Comput. Chem., 2001, 931; E. J. Baerends, J. Autschbach, D. Bashford, A. Bérces, F. M. Bickelhaupt, C. Bo,
P. M. Boerrigter, L. Cavallo, D. P. Chong, L. Deng, R. M. Dickson, D. E. Ellis, M. van Faassen, M. Fan, T. H. Fischer, C. Fonseca Guerra, A. Ghysels, A. Giammona, S. J. A. van Gisbergen, A. W. Götz, J. A. Groeneveld, O. V. Gritsenko, M. Grüning, F. E. Harris, P. Harris, P. van den Hoek, C. R. Jacob, H. Jacobsen, L. Jensen, G. van Kessel, F. Kootstra, M. V. Krykunov, E. van Lenthe, D. A. McCormack, A. Michalak, M. Mitoraj, J. Neugebauer, V. P. Nicu, L. Noodleman, V. P. O. Osinga, S. Patchkovskii, P. H. T. Philipsen, D. Post, C. C. Pye, W. Ravenek, J. I. Rodriguez, P. Ros, P. R. T. Schipper, G. Schreckenbach, M. Seth, J. G. Snijders, M. Solà, M. Swart, D. Swerhone, G. te Velde, P. Vernooijs, L. Versluis, L. Visscher, O. Visser, F. Wang, T. A. Wesolowski, E. M. van Wezenbeek, G. Wiesenekker, S. K. Wolff, T. K. Woo, A. L. Yakovlev and T. Ziegler, ADF2013.02, Vrije Universiteit, Amsterdam, 2013.

50 G. J. MacKay, R. S. Hemsworth and D. K. Bohme, Can. J. Chem., 1976, 54, 1624.

51 O. Mó, M. Yáñez, M. Decouzon, J.-F. Gal, P.-C. Maria and J.-C. Guillemin, J. Am. Chem. Soc., 1999, 121, 4653-4663.

52 J.-C. Guillemin, M. Decouzon, P.-C. Maria, J.-F. Gal, O. Mó and M. Yáñez, J. Phys. Chem. A, 1997, 101, 9525-9530.

53 J. C. Guillemin, E. H. Riague, J. F. Gal, P. C. Maria, O. Mó and M. Yáñez, Chem. - Eur. J., 2005, 11, 2145-2153.

54 S. C. Chmely, T. P. Hanusa and W. W. Brennessel, Angew. Chem., Int. Ed., 2010, 49, 5870-5874.

55 Y. Markus, J. Chem. Soc., Faraday Trans. 1, 1987, 83, 339343. 